\title{
Total Penectomy and Perineal Urethrostomy Management of Penile Squamous Cell Carcinoma with Paraffinoma in Single Center Hospital: A Rare Case Report
}

\author{
Syaeful Agung Wibowo ${ }^{1 *}$, Suharto Wijanarko ${ }^{1}$, Erwin Aritama Ismail ${ }^{2}$, Muhammad David Perdana Putra ${ }^{2}$ \\ ${ }^{1}$ Department of Surgery, Uro-Oncology Division, Sebelas Maret University, Surakarta, Indonesia; ${ }^{2}$ Departement of Surgery, \\ Sebelas Maret University, Surakarta, Indonesia
}

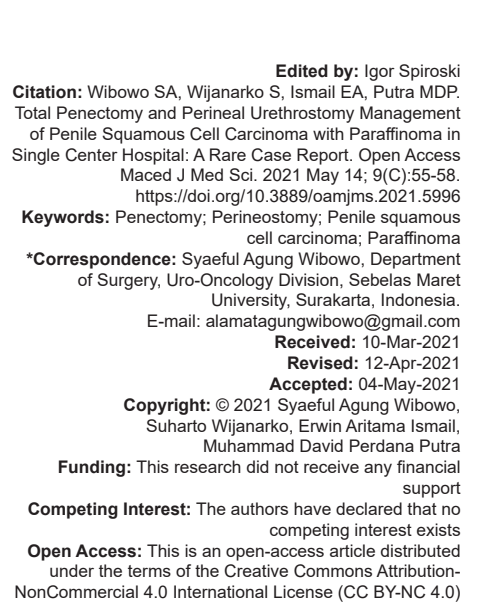

\section{Abstract}

BACKGROUND: Penile cancer is a rare condition, affecting less than $1 \%$ of the adult male population [1]. The risk of penile cancer increases significantly with age, poor hygiene, and the presence of the prepuce. The most common type encountered is squamous cell carcinoma (SCC). Clinically penile cancer appears as small lesions with induration and erythema or as large infiltrative ulcerative lesions. As the disease progresses, complaints such as itching, bleeding, discharge, foul odor, and pain occurred.

CASE REPORT: A 63-year-old man with poor hygiene and has a history of diabetes mellitus had penis ulcers since 5 years ago. On physical examination, an ulcer with the size of $12 \times 12 \times 10 \mathrm{~cm}$ was found growing pus (-). Biopsy had done and confirmed SCC as a result. Pelvic multiple slice CT shows growth covering the entire shaft of the penis down to the base. The patient had a previous history of using silicone injection 35 years ago and causing Sclerofibromatosis. The patient was planned to undergo surgery with clinical diagnosis T4NOM0. Total penectomy was performed with an elliptical incision around the base with a margin of $2 \mathrm{~cm}$. Sclerofibromatosis and the surrounding tissue were excised to the base of the penis followed by perineal urethrostomy. There was no problem postoperatively. The patient went home after staying in the hospital for $96 \mathrm{~h}$. The surgical specimen revealed SCC with free of tumor excision margin.

CONCLUSIONS: Injections with silicone to enlarge the penis cannot be justified. The process can trigger a chronic inflammatory reaction associated with penile malignancy. Total penectomy and wide excision with urethral perineostomy could be optimal initial treatment.

\section{Introduction}

Penile cancer is a rare condition, affecting less than $1 \%$ of the adult male population [1]. The risk of penile cancer increases significantly with age, poor hygiene, and the presence of the prepuce. The most common type encountered is squamous cell carcinoma (SCC). We know still lack of prevalence data from the incidence squamous cell cancer of the penis in Indonesia. Data in Indonesia (Hasan Sadikin Hospital Bandung) from 1975 to 1984 years the prevalence is 6 percent. Data from Cipto Mangunkusumo Hospital (Jakarta) and Dharmais Hospital (Jakarta) stated that there were 69 cases in 11 years (6.3 cases/year) [2].

Penile SCC is most commonly presented between the ages of 50 and 70 years. The majority of lesions are found on the glans (48\%), followed by the prepuce $(21 \%)$, both glans and prepuce $(15 \%)$, coronal sulcus $(6 \%)$, and shaft $(<2 \%)$ [3]. Clinically penile cancer appears as small lesions with induration and erythema or as large infiltrative ulcerative lesions. As the disease progresses, complaints such as itching, bleeding, discharge, foul odor, and pain occurred. Treatment may be delayed due to patient psychological factors, with an estimated $15-60 \%$ of patients delaying treatment for at least 1 year from the onset of lesions [3].

\section{Case Report}

A 63-year-old man with poor hygiene and has a history of diabetes mellitus had penis ulcers since 5 years ago. The patient had a previous history of using silicone injection 35 years ago and causing sclerofibromatosis. On physical examination, an ulcer with the size of $12 \times 12 \times 10 \mathrm{~cm}$ was found growing pus (-). The growth covers the entire shaft of the penis. Both testicles were enlarged (Figure 1). No lymph node enlargement detected. Biopsy had done with the sample from the part of the penis that has an ulcer, with the histopathologist result from Sragen General 
Hospital confirmed SCC. Pelvic multiple slice CT shows growth covering the entire shaft of the penis down to the base (Figure 2). Only the terminal portion of the corpora cavernosa is free of the lesions. Staging was performed by chest X-ray and abdominal CT showed normal pelvis. The patient was planned to undergo surgery with clinical diagnosis T4N0M0. Total penectomy was performed with an elliptical incision around the base. The fundiform and suspensory ligaments were cut and ligated. The deep dorsalis artery was ligated, the corpus was dissected up to the tip of the penis. A total penectomy was performed with a margin of 2 $\mathrm{cm}$ followed by perineal urethrostomy. There was no problem postoperatively. The patient went home after staying in the hospital for $96 \mathrm{~h}$. The surgical specimen revealed SCC with free of tumor excision margin.
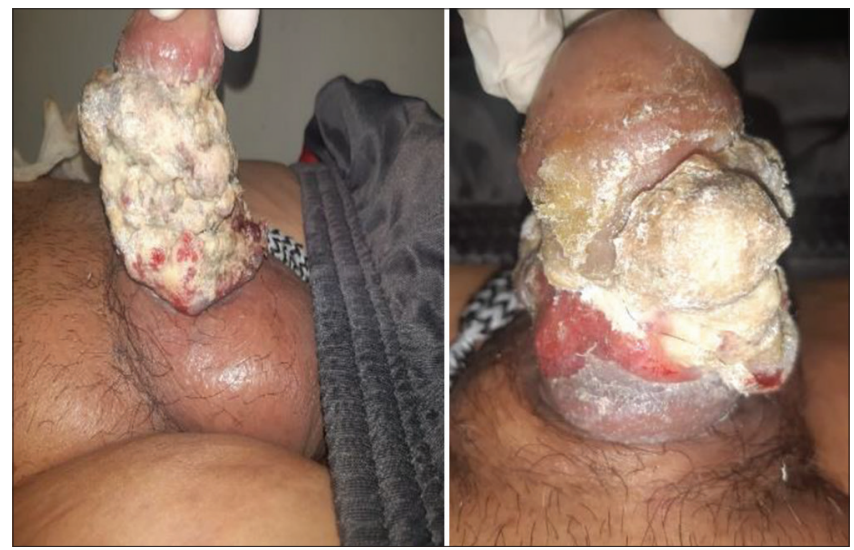

Figure 1: Sclerofibromatous lession through out the shaft to the corona

\section{Discussion}

The etiology of penile cancer has not been explained clearly; however, there are conditions associated with penile cancer such as uncircumcised prepuce, chronic inflammatory conditions, and exposure to the human papilloma virus [4]. Poor hygiene, history of smoking, and history of phimosis were also found in $25 \%$ of patients with penile cancer [5]. Many cases of sclerofibroma reactions and advanced granulomas occurring after injection of liquid silicone were given to enlarge the penis [6]. Penile granulomas can occur after injection of high viscosity fluids, such as liquid silicone (siliconoma), paraffin (paraffinoma), Vaseline, or other mineral oils. Paraffinoma is a granulomatous foreign body reaction that results from the injection of oily substances containing long-chain acyclic hydrocarbons [7]. Paraffinoma has a distinctive histopathological pattern that demonstrates the substitution of normal subcutaneous tissue by cystic spaces of different sizes [8]. Penile granulomas and fibromas are rare cases of having a proper treatment [9]. In this case, the granuloma and fibromatosis in the

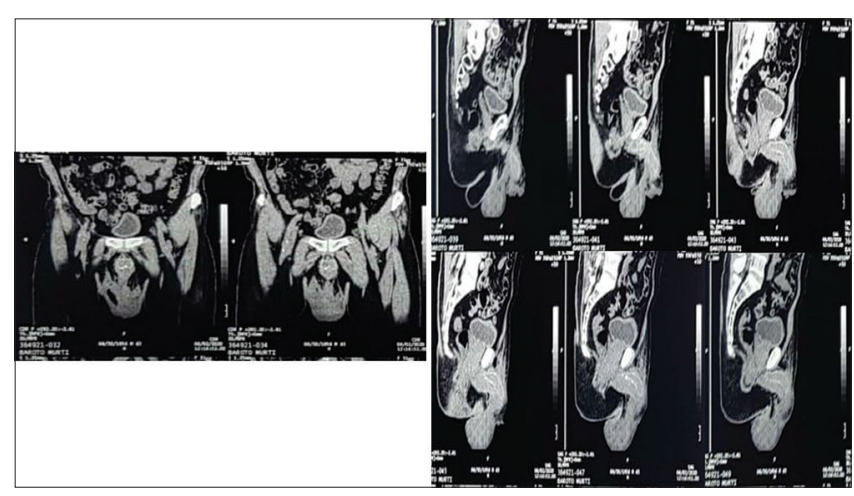

Figure 2: Contrast pelvic multiple slice computed tomography shows mass growth Pelvic CT Scan with Contrast shows mass growth from glans, entire shaft of the penis down to the scrotum

patient developed into SCC which associated with chronic inflammation [10].

A 63-year-old man was reported with penile sclerofibromatosis and penile SCC with a previous history of using silicone injection 35 years ago. Sclerofibromatosis and the surrounding tissue were excised to the base of the penis. From the Alison et al. study for penile paraffinoma, a total of 124 cases have been reported with a mean age of 36.3 years (range 17-71 years). The majority originated in Korea (31.7\%), Bulgaria (19.8\%), and Hungary (14.3\%; Figure 3 ). A variety of materials were injected, with the most common being liquid paraffin $(80.2 \%)$. Silicone was used in $4 \%$, Jamaica oil in $3.2 \%$, mineral oil in $4.8 \%$, baby oil in $2.4 \%$, mechanical oil in $1.6 \%$, and melted lipstick in $0.8 \% ; 3.2 \%$ used an undetermined substance. The median interval between injection and presentation was 24 months. Patients presented with a variety of symptoms, including penile pain and swelling $(30.2 \%)$, ulceration $(15.4 \%)$, and deformity $(11.4 \%)$. Foreskin-related problems occurred in $8.7 \%$ (one non-reducible paraphimosis and 10 phimosis cases) and voiding dysfunction in $5.4 \%$. Potentially lifethreatening complications were gangrene and sepsis with palpable inguinal lymphadenopathy $(4.7 \%)$ and there was one case of penile SCC associated with paraffinoma 35 years following injection of mineral oil [2].

A total penectomy was performed and continued by perineal urethrostomy. There were no complications after surgery. It was concluded that the injection of liquid silicone to enlarge the penis can cause chronic inflammatory reactions. Silicone is a polymer that can be chemically injected into the soft tissue of the penis which forms into liquid silicone in the form of injection in a variety of cosmetic procedures [5]. Mainly done for tissue augmented, for example, lips, chin, breasts, buttocks, and penis. Liquid silicone has been associated with various side effects of inflammatory reactions, sometimes causing tissue destruction [3]. Most of the treatment 


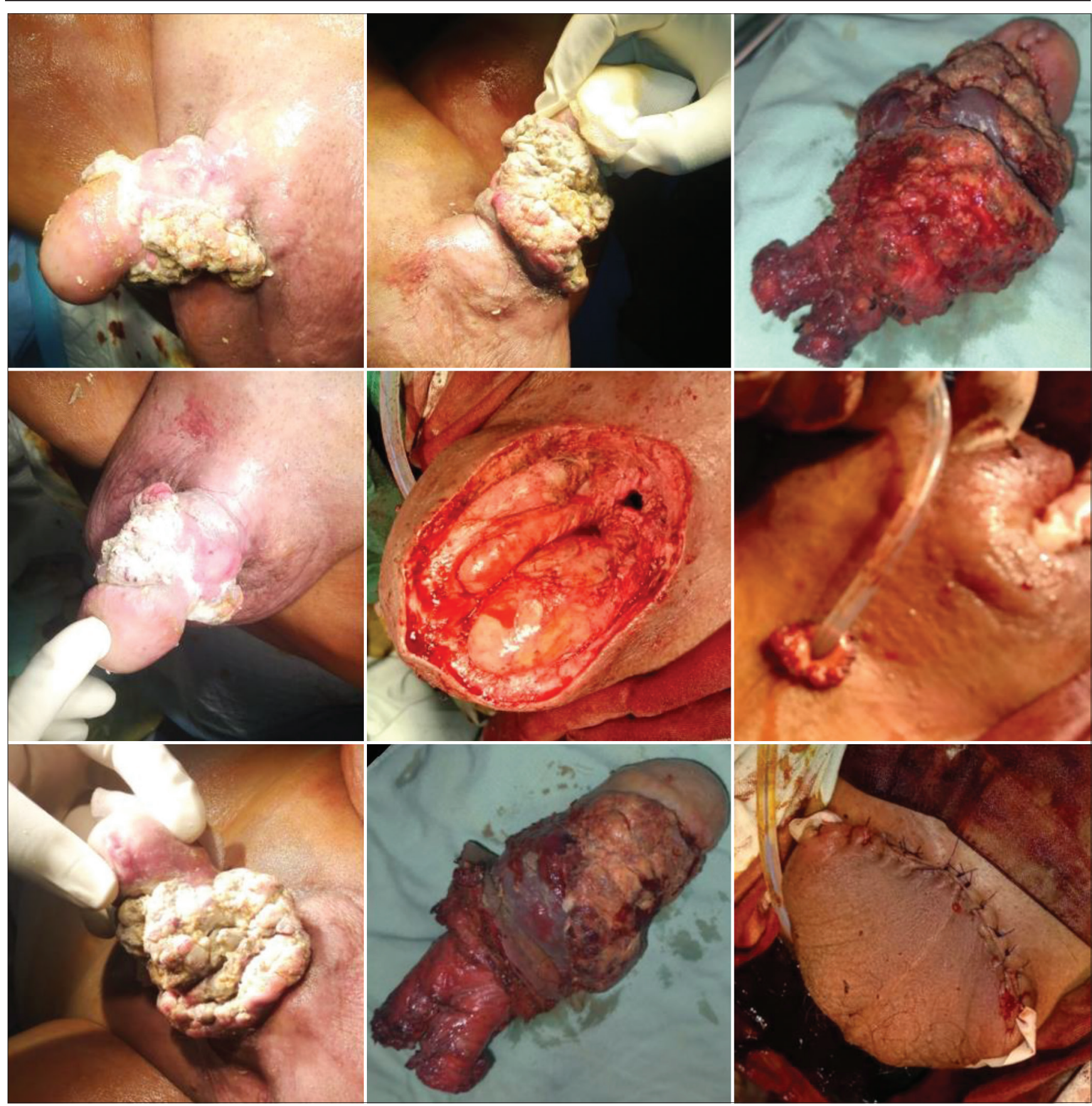

Figure 3: Total penectomy was performed with intraoperative frozen section (for intraoperative surgical margin assessment). Sclerofibromatosis and the surrounding tissue were excised to the base of the penis and affected scrotum followed by perineal urethrostomy

is a preservation method. Another alternative can be done, such as partial and total penectomy for cases of advanced-stage penile cancer or in cases of penile cancer that is more proximal [3] The rate of morbidity both functionally and psychologically is a determining factor in surgical management [11]. Total penectomy includes excision of the penis to the suspensory ligament, maintaining the proximal corpora cavernosa [12]. Radical penectomy is performed less frequently, including excision of the penis by removing the entire body. As a follow-up, the urethra will be removed through a perineal urethrostomy to allow voiding while sitting or squatting [12].

\section{Conclusions}

Penile cancer is a rare condition, affecting less than $1 \%$ of the adult male population. The risk of penile cancer increases significantly with age, poor hygiene, chronic inflammatory condition, uncircumcised prepuce, and history of phimosis. History of silicon injection to the penis can trigger a chronic inflammatory reaction that in this cased associated with penile malignancy. Total penectomy and wide excision with urethral perineostomy could be an optimal initial treatment in penile cancer with paraffinoma with clinical finding 
sclera fibromatous lesions entire shaft until the base of the penis.

\section{References}

1. Kiptoon DK, Ngugi PM, Rana FS. Cancer of the penis: Case report. East Afr Med J. 2009;86(4):196-200. https://doi. org/10.4314/eamj.v86i4.46952

PMid:20085006

2. Tanti Y, Muhartono M. A 59 years old man wit penile. J Medula Unila. 2016;5(2):103-7.

3. Solakhan M, Bulut E. Penile cancer: Case report. Int Arch Urol Complications. 2018;4(2):45.

4. Silberstein J, Downs T, Goldstein I. Penile injection with silicone: Case report and review of the literature. J Sex Med. 2008;5(9):2231-7.

PMid:18657262

5. O'Neill S, Barns M, Vujovic F, Lozinskiy M. The role of penectomy in penile cancer-evolving paradigms. Transl Androl Urol. 2020;9(6):3191-4. https://doi.org/10.21037/tau.2019.08.14 PMid:33457290

6. Dachlan I. Penile granuloma caused by liquid silicone injection.
J Med Sci. 2007;39(1):53-8.

7. Loughlin KR. Surgical management of penile carcinoma: The primary lesion. BJU Int. 2006;97(3):655-67. https://doi. org/10.1111/j.1464-410x.2006.06077.x

PMid:16469049

8. Yadav K. Radical penectomy: Procedure details of an uncommonly performed procedure for carcinoma penis and review of literature. Cancer Rep Rev. 2018;2(2):2-2. https://doi. org/10.15761/crr.1000149

9. Shaeer O, Shaeer K. Delayed complications of gel injection for penile girth augmentation. J Sex Med. 2009;6(7):2072-8. https:// doi.org/10.1111/j.1743-6109.2009.01262.x PMid: 19453922

10. Ghahhari J, Marchioni M, Spiess PE, Chipollini JJ, Nyirády $P$, Varga J, et al. Radical penectomy, a compromise for life: Results from the PECAD study. Transl Androl Urol. 2020;9(3):1306-13. https://doi.org/10.21037/tau.2020.04.04 PMid:32676414

11. Kim HK, Kim BJ, Kim MN, Kim SY, Kim SE, Mun SK, et al. Facial paraffinoma treated with a bipolar radiofrequency device. Int J Dermatol. 2015;54(1):89-91. https://doi. org/10.1111/j.1365-4632.2012.05844.x

PMid:24899152

12. Downey AP, Osman NI, Mangera A, Inman RD, Reid SV Chapple CR. Penile paraffinoma. Eur Urol Focus. 2019;5(5):8948. https://doi.org/10.1016/j.euf.2018.06.013

PMid:30007541 